\title{
EDITORIAL
}

\section{Goodbye and thanks for the memories}

This is a U.S. government work and not under copyright protection in the U.S.; foreign copyright protection may apply 2022

Prostate Cancer and Prostatic Diseases (2022) 25:1-2; https://doi. org/10.1038/s41391-022-00500-1

It is with bittersweet feelings that I write this last editorial as Editorin-Chief of Prostate Cancer and Prostatic Diseases. I remember the day in May 2010 when I was offered the job: it was one of the most exciting professional days in my career. I was taking over a very solid journal from two icons in the field: Drs. Judd Moul (who was my boss at the time) and Roger Kirby. I knew I had big shoes to fill, but I was full of new ideas.

In my initial editorial [1], five priorities were identified for the journal: (1) peer-review time; (2) time to publication; (3) high-quality papers; (4) visibility; and (5) making the journal more user friendly. I am proud to say that during my tenure we made major strides toward all five goals.

1. Peer-review time. In 2021, despite the COVID-19 pandemic, an increasing number of submissions (up nearly 3 -fold since 2010), and despite more people saying no to reviewing, the median time to decision is currently 11 days. Nearly $80 \%$ of decisions occur within 28 days, and $90 \%$ of decisions within 40 days.

2. Time-to-publication. One of the biggest hurdles to timely publication is time to acceptance. By making that a priority, we dramatically shortened review times. For papers that are favorably reviewed, the median time to a decision is now $\sim 30$ days and median time to acceptance once a revision is submitted is seven days. Thus, an accepted paper spends approximately only 37 days under review. The average time from acceptance to being viewed online is even shorter at 24 days.

3. High-quality papers. It is always tough to measure the quality of papers. While no metric is perfect, the most often used metric is impact factor. As such, it is noteworthy that in 2010, when I started, the journal had an impact factor of 2.263, was ranked in the $3^{\text {rd }}$ quartile in Oncology journals and was in the $2^{\text {nd }}$ quartile in Urology and Nephrology journals. In 2021, our impact factor is 5.554 (a nearly $150 \%$ growth) and we currently rank in the $2^{\text {nd }}$ quartile for Oncology journals and the $1^{\text {st }}$ quartile for Urology and Nephrology Journals.

4. Visibility. Our Twitter account, which did not exist in 2010, now has over 1,700 followers. Our downloads for 2021 are just shy of 350,000 . Total webpage views for 2021 are $\sim 545,000$.

5. User friendly. This is what I am most proud of. I have been able to have open and frank discussions with many authors over the years. I've discovered the value of making time to explain the reasoning behind decisions made through our peer-review process. For every paper we reject without review, we provide a short rationale that hopefully can be used to make the paper better. This has been a springboard for authors to reach out and have a more extended discussion about their work. Indeed, I got to first know one of my now dear friends, and current Associate Editor, Henry Woo, through exactly such an exchange.

More than the accomplishments, from the past 11.5 years, I will remember the people. I have been privileged to work with some of the finest Associate Editors and editorial board anyone could ask for. They are not just work colleagues, but close friends. They have kept me honest and humble, and I am very much in their debt. Indeed, in recent years as the reputation and metrics of the journal have climbed, I am often overruled by our Associate Editors. As such, this means good papers are being rejected and for that, we apologize. However, as the journal has grown, we cannot accept papers that are just "good". We are looking for great papers.

In addition to our editors, our reviewers are outstanding. They devote their time selflessly asking for nothing in return. To you, I salute you. You are the true backbone of any journal without which there would be no peer-review process.

The editorial support for the journal is superb. It is truly a very well-run journal. I am particularly appreciative of our current managing editor, Rebecca Shreeve, who has let me stay on and allowed me to leave on my own time and on my own terms. Thank you for your support of the journal and your friendship over the years.

I would like to congratulate Cosimo de Nunzio, MD, my successor, in taking over the journal. Cosimo - you are a dear friend who I have known for over 15 years. I remember spending time with you and your family in Rome and you showing me around. We have had the opportunity to collaborate, and you even sent one of your medical students to work with me at Duke for 2 months. I could not imagine a better person or better leader to pick up the torch and take the journal to even greater heights.

Finally, to you, the readers. Thank you for being on this journey with me for the last decade. It has been an honor to be your editor. I have always strived to "do the right thing" and hopefully that has shown. However, as "time waits for no man", it is time for me to bid you adieu. Take care, be safe, and thanks for the incredible memories.

Your humble, soon-to-be editor emeritus,

Steve

Stephen J. Freedland ${ }^{1,2}$ 屁

${ }^{1}$ Division of Urology, Cedars-Sinai Medical Center, Los Angeles, CA, USA. ${ }^{2}$ Section of Urology, Durham VA Medical Center, Durham, NC, USA. ${ }^{凶}$ email: Stephen.freedland@cshs.org

\section{REFERENCE}

1. Freedland SJ. Editor's comments. Prostate Cancer Prostatic Dis. 2011;14:191. 
COMPETING INTERESTS

The author declares no competing interests.

ADDITIONAL INFORMATION

Correspondence and requests for materials should be addressed to Stephen J. Freedland.
Reprints and permission information is available at http://www.nature.com/ reprints

Publisher's note Springer Nature remains neutral with regard to jurisdictional claims in published maps and institutional affiliations. 